DOI: $10.20396 /$ cel.v62i0.8657999

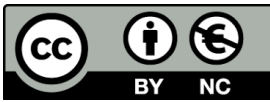

\title{
ADJETIVOS STAGE-LEVEL E INDIVIDUAL-LEVEL EM CONSTRUÇÕES DEPICTIVAS
}

\author{
STAGE-LEVEL AND INDIVIDUAL-LEVEL ADJECTIVES IN \\ DEPICTIVE CONSTRUCTIONS
}

\author{
ELISABETE FERREIRA ${ }^{1}$
}

\begin{abstract}
RESUMO: Neste trabalho, revejo a proposta de análise apresentada em Ferreira (2017) para construções de predicação secundária depictiva, como $O$ João leu a carta cansado. Mais especificamente, rejeito a hipótese de Ferreira (2017) de que, em tais sentenças, nas quais ocorreria adjunção de uma small clause aspectual à oração matriz, uma categoria funcional Asp atribuiria a propriedade stage-level a um adjetivo como cansado. Neste artigo, defendo que a relação entre Asp e o adjetivo não seja de atribuição de propriedade, mas de compatibilidade de traços semânticos na seleção, e que o adjetivo entraria na derivação carregando a informação de que veicula uma propriedade transitória ou permanente. Nesse sentido, suponho que essas construções de predicação secundária possam apresentar um dos dois tipos de Asp: um que entra na derivação com um subconjunto de traços semânticos [+PERs], que denota persistência temporal e seleciona adjetivos individual-level, ou um que entra na derivação com o subconjunto [-PERs], que denota eventualidade temporária e seleciona adjetivos stage-level. Em minha argumentação, recorro a McNally (1993) e a Cinque (2010): a primeira, para tratar de predicações secundárias com predicados individual-level e da influência da pragmática nesses contextos; o último, para tratar brevemente de adjetivos stage-level e individual-level no âmbito do DP.

Palavras-chave: construções depictivas; predicados stage-level; predicados individual-level.
\end{abstract}

\begin{abstract}
This paper revises Ferreira's (2017) analysis of depictive secondary predicate constructions, such as $O$ João leu a carta cansado ('John read the letter tired'). More specifically, I reject Ferreira's (2017) hypothesis to such sentences, which suggests the adjunction of an aspectual small clause to the main clause, to which the functional category Asp would attribute the stage-level property to an adjective like cansado ('tired'). In this paper, I defend that the relation between Asp and the adjective is not one of property attribution, but rather one of semantic feature compatibility at selection; I also defend that the adjective enters the derivation bearing the information about the type of property it conveys (permanent or temporary). Hence, I assume that depictive secondary predicate constructions may contain one of two types of Asp: one which enters the derivation with a subset of semantic features [+PERS], which denotes temporal persistence and selects individual-level adjectives, or one which enters the derivation with the subset [-PERS], which denotes a temporary eventuality and
\end{abstract}

${ }^{1}$ Doutoranda em Linguística pelo Programa de Pós-Graduação em Linguística (PPGL) da Universidade de Brasília, UnB, Brasília, DF, Brasil. elisabete.morais.ferreira@gmail.com.

Orcid: https://orcid.org/0000-0003-4630-6761.

Agradeço aos dois pareceristas anônimos deste texto por suas observações, sugestões e críticas. Registro também meus agradecimentos à Helena Guerra Vicente, à Bruna Moreira, ao Marcus Lunguinho, ao Julio Barbosa e ao Paulo Medeiros Júnior por suas contribuições ao discutirem comigo alguns aspectos deste artigo e da minha pesquisa de Doutorado em andamento, da qual este trabalho é fruto. Quaisquer erros são de minha responsabilidade. 
selects stage-level adjectives. I draw upon the works of McNally (1993) and Cinque (2010): the former, to discuss secondary predicate constructions with individual-level adjectives and the pragmatic notions involved in these contexts; the latter, to briefly deal with stage-level and individual-level adjectives within the DP.

Keywords: depictive constructions; stage-level predicates; individual-level predicates.

\section{INTRODUÇÃO}

Nas chamadas construções depictivas como (1a), em que um mesmo argumento $(O$ João) é partilhado pelo predicado da oração matriz (leu) e pelo predicado secundário (o depictivo cansado), o adjetivo expressa um estado de um participante da oração principal que coincide temporalmente com o momento em que ocorre a eventualidade denotada pelo predicado da oração matriz (HALLIDAY, 1967, p. 63; SCHULTZE-BERNDT; HIMMELMANN, 2004, p. 60; ROTHSTEIN, 2006, p. 210). ${ }^{2}$ Assume-se comumente que esse tipo de predicado secundário veicula uma propriedade transitória - stage-level, na terminologia de Carlson (1977). Assim, (1a) recebe a interpretação da paráfrase em (1b), construída com a cópula estar.
(1) a. O João leu a carta cansado.
b. O João estava cansado quando leu a carta.

A hipótese de que esses predicados secundários devem, necessariamente, ser adjetivos com uma leitura stage-level explicaria o contraste entre (1a) e (2): por veicular uma propriedade transitória, cansado seria licenciado nessa construção, ao passo que inteligente, que denota uma interpretação individual-level, propriedade não transitória, tornaria a sentença (2) inaceitável dita fora de contexto.

\section{(2) *O João leu a carta inteligente.}

Em Ferreira (2017), assumi a hipótese de que a interpretação stage-level apresentada por um adjetivo como cansado em (1a) seria codificada no âmbito

${ }^{2}$ O termo "depictivo", introduzido por Halliday (1967), é utilizado na literatura tanto em referência a adjetivos que se orientam ao sujeito quanto a adjetivos que se orientam ao objeto em construções de predicação secundária como as ilustradas em (i) e (ii) a seguir, retiradas de Rothstein (2006, p. 210).

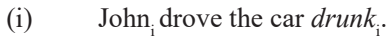
(depictivo orientado ao sujeito)
'John dirigiu o carro bêbado'.
(ii) Mary ate the carrots uncooked $_{\mathrm{i}}$.
'Mary comeu as cenouras cruas/não cozidas'.
(depictivo orientado ao objeto) 
de uma small clause aspectual AspP, adjungida à oração matriz. ${ }^{3}$ Nessa análise, a categoria funcional Asp seleciona um sintagma AP que, por sua vez, contém o adjetivo e o DP, que se move para spec de AspP, conforme (3a), após estabelecer uma relação de concordância com Asp. Em seguida, o adjetivo se moveria de dentro do AP e se adjungiria a Asp, onde receberia a morfologia de concordância relevante e a interpretação stage-level, conforme (3b).
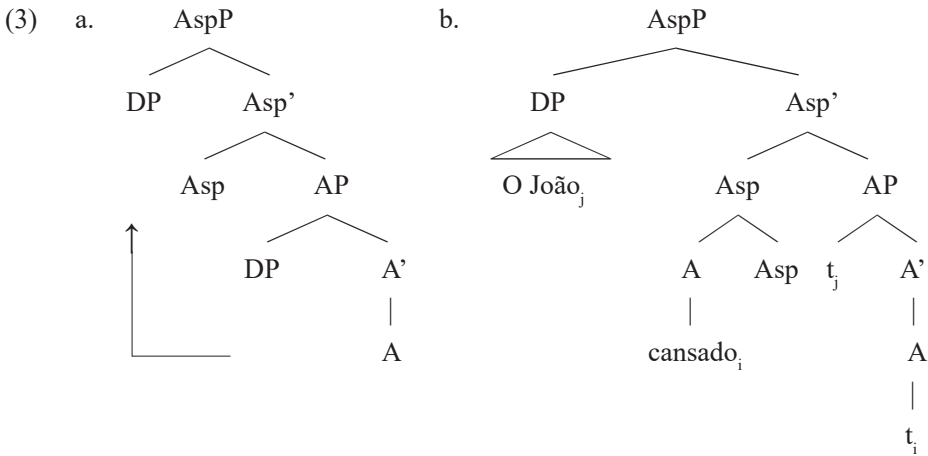

(FERREIRA, 2017, p. 182, 187)

Essa análise, no entanto, enfrenta alguns problemas, como apontado em nota em Ferreira (2017, p. 201). Se Asp é o núcleo responsável por conferir a interpretação stagelevel ou individual-level ao adjetivo contido na categoria que toma como complemento, isso implica que esse tipo de interpretação não é parte da informação lexical contida nos adjetivos. Com isso, a previsão é a de que todos os adjetivos podem, em princípio, ser interpretados como stage-level ou individual-level. Contudo, esse não parece ser o caso; se assim o fosse, como explicaríamos o fato de que certos adjetivos têm apenas (ou ao menos tipicamente) interpretação transitória (como grávida, bêbada) e outros, apenas (tipicamente) a não transitória (como mamífero, inteligente)?

Consequentemente, como essa hipótese explicaria o contraste entre (1a), com o predicado stage-level cansado, e (2), em que inteligente não veicula uma propriedade transitória? ${ }^{4}$ Em outras palavras, por que, nessas sentenças, o núcleo

${ }^{3}$ Cabe esclarecer que a representação sintática de construções depictivas é matéria de debate na literatura. Nesse sentido, questiona-se comumente se a representação dessa relação de predicação secundária envolveria a formação de um constituinte small clause (minioração) pelo depictivo e seu sujeito (cf. STOWELL, 1983; WILLIAMS, 1980; ROTHSTEIN, 1983; LEGENDRE, 1997; FOLTRAN, 1999; entre outros). Assumo neste trabalho, assim como assumi em Ferreira (2017), a hipótese de que o depictivo e o seu sujeito constituem, de fato, uma small clause, que se adjunge à oração matriz - sendo o sujeito da small clause um DP que sofrerá sideward movement (movimento lateral), nos termos de Nunes (2004, entre outros). A respeito disso, remeto o leitor ao capítulo 2 de Ferreira (2017), no qual apresento argumentos favoráveis à hipótese da formação de uma small clause nessas construções. Agradeço a um dos pareceristas deste artigo por apontar a necessidade de deixar claro esse ponto.

${ }^{4}$ No caso dos dados (1a) e (2), o julgamento de gramaticalidade considera uma leitura fora de contexto (out of the blue). Conforme será discutido a seguir, sentenças como (2), com um adjetivo individual-level, podem ser aceitas em determinados contextos. 
Asp conferiria uma interpretação stage-level a cansado, mas não seria capaz de selecionar o adjetivo inteligente e conferir também a ele esse tipo de propriedade? O que barraria esse tipo de derivação? Tais questionamentos ficam em aberto nessa proposta, o que põe em xeque a própria postulação de uma categoria Asp para essas construções: de fato, diante dessas considerações, não parece haver necessidade de postular especificamente uma projeção Asp em predicações secundárias, em vez de qualquer outra categoria funcional. Neste trabalho, parto dessas questões para modificar a análise em Ferreira (2017).

A seguir, delimito alguns ambientes sintáticos em que ocorrem adjetivos stage-level e individual-level. Discorro, a partir de McNally (1993) e Cinque (2010), sobre o fato de que esses dois tipos de adjetivo podem ocorrer tanto em ambientes de predicação secundária, em que o adjetivo é um predicado que apresenta uma estrutura argumental, quanto internamente ao DP, em que o adjetivo estabelece com o nome somente uma relação de atribuição. ${ }^{5}$ Assumo que esses dois tipos de ambiente diferem fundamentalmente quanto à categoria Asp: esta estaria presente apenas em predicações secundárias, e não dentro do DP, visto que Asp relaciona eventualidades de duas predicações. ${ }^{6}$

Supondo que Asp pode entrar na derivação de construções de predicação secundária com um subconjunto de traços semânticos [+PERs], que denota persistência temporal, ou com um subconjunto [-PERS], que denota eventualidade temporária (não persistência), proponho, em seguida, um esboço de análise que condiciona a possibilidade de um adjetivo ser selecionado por um desses dois "tipos" de Asp à natureza do traço semântico que esse item lexical já traz consigo ao entrar na derivação: adjetivos com traços individual-level seriam compatíveis apenas com Asp [+PERS], enquanto adjetivos com traços stage-level seriam compatíveis somente com [-PERs]. ${ }^{7}$ Isso significa que, nesta nova proposta, não é Asp que atribui a propriedade individual-level ou stage-level ao adjetivo, mas este já entraria na derivação com a informação de que ele veicula uma propriedade permanente ou temporária. Suponho, ainda, a partir de McNally (1993), que a relevância pragmática é um dos fatores capazes de licenciar Asp [+PERs] em predicações secundárias. Com essa discussão, espero fornecer um caminho para motivar a postulação de Asp em construções depictivas e responder aos referidos questionamentos.

${ }^{5}$ Isso significa que assumo neste trabalho, com McNally (1993), que adjetivos individual-level podem, sim, ocorrer em predicações secundárias depictivas. Como será explicado mais adiante, de acordo com a visão da autora, quando um adjetivo individual-level aparece nessas sentenças, não ocorre uma coerção interpretativa do adjetivo para que ele tenha uma leitura stage-level nesses contextos.

${ }^{6}$ Emprego neste trabalho o termo "eventualidade", seguindo a terminologia introduzida por Bach (1986), em referência tanto à noção de estado quanto à noção de evento, e também utilizo o termo "evento" de modo informal.

${ }^{7}$ Para ser mais exata, refiro-me à seleção do sintagma adjetival por Asp. 


\section{DOIS AMBIENTES SINTÁTICOS PARA ADJETIVOS STAGE- LEVEL E INDIVIDUAL-LEVEL}

Assumo neste trabalho a hipótese de que, ao entrar na derivação, um adjetivo já contém em si a informação de que ele veicula uma propriedade stage-level ou individual-level. Formalmente, isso poderia ser traduzido em termos de traços semânticos contidos nesse item lexical. Em certo sentido, essa intuição é captada por Bisol (1975) em seu estudo sobre predicados complexos. A autora distingue adjetivos que expressam "propriedades inerentes", tais como alto, grande e redondo, daqueles que expressam propriedades "não inerentes", como triste e atrasado (BISOL, 1975, p. 29). Estes, segundo a autora, ocorreriam com a cópula estar; os primeiros, supõe-se, ocorreriam com a cópula ser. ${ }^{8}$ Neste trabalho, interpreto essa inerência de que trata Bisol em termos de transitoriedade. Assim, seguindo McNally (1993), entendo que adjetivos stage-level denotam propriedades transitórias, enquanto adjetivos individual-level veiculam propriedades permanentes. Esse entendimento está subjacente à discussão que faço nas seções a seguir.

\subsection{Predicação secundária}

Como dito anteriormente, adjetivos stage-level ocorrem em ambiente de predicação secundária depictiva, fato amplamente atestado na literatura, em diferentes línguas do mundo (cf. SCHULTZE-BERNDT; HIMMELMANN, 2004). Nesse tipo construção, o predicado secundário expressa um estado de seu referente no momento em que se dá o estado de coisas descrito pelo predicado principal (McNALLY, 1993, p. 3). ${ }^{9}$ Assim, a sentença em (4a), com o predicado secundário orientado para sujeito, pode ser parafraseada como Maria estava bêbada quando dirigiu seu carro, e (4b), com depictivo de objeto, pode ser parafraseada como $O s$ vegetais estavam crus quando nós os comemos. ${ }^{10,11}$

\footnotetext{
${ }^{8}$ Ao tratar das cópulas ser e estar no espanhol, tidas comumente como os expoentes lexicais da distinção individual-level / stage-level, Maienborn (2005a) argumenta contra a ideia de que o sistema gramatical é sensível a oposições conceituais como "permanente vs. temporário". Com base em considerações de natureza semântica e pragmática, a autora defende haver, na realidade, uma preferência pela interpretação de predicações com ser como veiculadoras de propriedades permanentes e de predicações com estar como denotadoras de propriedades temporárias. Os resultados da autora podem ser importantes para a discussão proposta neste artigo, mas deixo para trabalhos futuros um aprofundamento sobre a questão.

${ }^{9}$ Neste trabalho, entenda-se predicado secundário como termo equivalente a depictivo, apesar de haver outros tipos de predicado comumente classificados como secundários, como os resultativos, que não são abordados aqui.

${ }^{10}$ Os dados (4b) e (5b) são traduções de sentenças em inglês apresentadas em McNally (1993, p. 2) - respectivamente, We ate the vegetables raw e ?? We ate the vegetables organic.

${ }^{11}$ É importante observar que sentenças com a ordem linear como a que se encontra em (4b) são ambíguas no português brasileiro, com leituras associadas a estruturas sintáticas distintas. Uma interpretação possível para a referida construção é a da chamada leitura atributiva, equivalente à sentença do inglês We ate the raw vegetables. Outra interpretação possível corresponde à sentença We ate the vegetables raw: é este tipo de interpretação - a leitura depictiva — que tenho em mente ao tratar de dados como (4b) neste trabalho.
} 
(4) a. [A Maria $]_{i}$ dirigiu seu carro bêbada

b. Nós comemos [os vegetais $]_{\mathrm{i}}$ crus.

Aparentemente, predicados secundários devem veicular uma leitura transitória, stage-level. Isso explicaria a agramaticalidade dos dados em (5), com adjetivos individual-level. ${ }^{12}$
a. *A Maria dirigiu seu carro inteligente.
b. *Nós comemos os vegetais orgânicos.

Para explicar essa aparente obrigatoriedade, Rapoport (1991 apud McNALLY, 1993) recorre à representação lógico-semântica desses predicados. Para a autora, essas construções devem obedecer a um princípio segundo o qual um predicado secundário deve apresentar um argumento neodavidsoniano, ou seja, um argumento espaço-temporal. Conforme explica McNally (1993, p. 3-4), para Rapoport, o predicado secundário somente é licenciado se um argumento evento em sua estrutura temática estiver ligado a um argumento evento na estrutura temática do predicado principal. Somente predicados stage-level apresentariam esse argumento neodavidsoniano, razão pela qual predicados individual-level não podem aparecer nesse tipo de construção. ${ }^{13,14}$

McNally (1993), no entanto, recusa a hipótese de Rapoport de que predicados secundários devem, necessariamente, expressar uma propriedade stage-level, transitória. A autora mostra que propriedades individual-level também podem aparecer nessas construções, como revelam os dados (6) a (11), do inglês. ${ }^{15}$

(6) a. The neighbor's girls entered the Army enthusiastic advocates of U.S. interventionism.

'As meninas do vizinho entraram no Exército defensoras entusiastas do intervencionismo norte-americano'. é perfeita.

${ }^{12}$ Ressalto: (5b) é agramatical/inaceitável na leitura depictiva. Na leitura atributiva, a sentença

${ }^{13}$ A proposta apresentada nesse período, seguida por Rapoport, é de Kratzer (1995), texto datado de 1995, mas originalmente escrito em 1988.

${ }^{14}$ Maienborn $(2005 b$, 2007) realiza uma distinção entre dois tipos de estado, cujas propriedades ontológicas e linguísticas são distintas: estados davidsonianos, no sentido de Davidson (1967), e estados kimianos. Nessa perspectiva, verbos de estado (state verbs), como sentar e dormir, denotariam eventualidades davidsonianas, apresentando um tipo de argumento evento que pode ser localizado no tempo e no espaço. Por outro lado, verbos estativos (stative verbs), como saber, pesar e possuir, denotariam um estado kimiano, não podendo ser localizados no espaço, apenas no tempo. Embora essa distinção possa ser relevante para este trabalho - e, de fato, há discussões a respeito de que tipo de estado um adjetivo denotaria - , ela não será explorada aqui. Por ora, não assumo nenhum posicionamento a esse respeito, deixando para trabalhos futuros um estudo mais aprofundado sobre a relação entre essa distinção e a proposta aqui desenvolvida.

${ }^{15}$ Os dados referidos foram extraídos de McNally (1993, p. 4). 
b. They left the Army fervent noninterventionists.

'Elas saíram do Exército não intervencionistas fervorosas'.

(7) George was a Presbyterian for years. Today he's sitting in church a convert to Catholicism.

'George foi presbiteriano (literalmente: um presbiteriano) durante anos. Hoje ele está sentado na igreja converso (literalmente: um converso) ao Catolicismo'.

(8) My dad was born compulsive and will die compulsive.

'Meu pai nasceu compulsivo e vai morrer compulsivo'.

(9) The monster was a gentle soul until Dr. Frankenstein operated a second time. He arose from the operating table malevolent and vengeful.

'O monstro era uma alma gentil até Dr. Frankenstein operá-lo pela segunda vez. Ele se levantou da mesa de cirurgia malévolo e vingativo'.

(10) The tablecloth went to the cleaners white and came back yellowish.

'A toalha de mesa foi para a lavanderia branca e voltou amarelada'.

(11) George Bush was born a Republican, and they will bury him a Republican. 'George Bush nasceu republicano (literalmente: um republicano), e vão enterrá-lo republicano (literalmente: um republicano)'.

Nota-se, pela tradução apresentada abaixo de cada exemplo, que os dados equivalentes em português brasileiro se comportam de forma semelhante ao inglês, no sentido de que também admitem predicados individual-level como predicados secundários.

A respeito desses dados, McNally (1993, p. 5) afirma que, com exceção dos dados com predicados que expressam nascimento e morte, todas as sentenças geram uma implicatura conversacional de que o evento expresso pelo predicado principal marca uma fronteira (um limite) contextualmente significante logo após o começo ou imediatamente antes do fim do intervalo de tempo durante o qual se dá a eventualidade denotada pelo predicado secundário. ${ }^{16}$ Assim, argumenta a autora, infere-se do dado (6a) que a entrada das meninas no Exército precedeu o fim de sua defesa do intervencionismo (McNALLY, 1993, p. 5). Esse tipo de implicatura não é obtido com predicados secundários stage-level; em (4a), nada

${ }^{16}$ Embora McNally (1993) não discorra sobre o significado da expressão conversational implicature (implicatura conversacional), pode-se, para os propósitos deste trabalho, defini-la, grosso modo, como uma informação implícita associada à interpretação da sentença. A esse respeito, ver Grice (1975). 
se infere sobre o estado de Maria em qualquer outro tempo além do intervalo temporal demarcado pelo predicado principal.

Uma possibilidade de explicação dos dados (6) a (11), conforme explica a autora, é a de que certos predicados individual-level, quando aparecem como predicados secundários, são forçados a ter uma interpretação stage-level, em uma espécie de coerção interpretativa, como já se defendeu na literatura (cf. FOLTRAN, 1999). McNally (1993, p. 5), contudo, rejeita essa explicação: segundo a autora, para que as sentenças (6) a (11) sejam boas, não é necessário que o predicado secundário veicule uma propriedade transitória; consequentemente, não há necessidade de nenhum contexto especial para forçar a interpretação desses predicados. Além disso, ainda segundo a autora, se as referidas sentenças apresentassem uma interpretação stage-level, seria de se esperar que a referida implicatura conversacional não existisse, o que é contrário aos fatos.

Para explicar por que, então, certas sentenças construídas com predicados secundários individual-level são ruins, como (5a) e (5b), e outras são boas, como (6) a (11), McNally (1993) recorre às noções pragmáticas de informatividade e relevância. Além disso, a autora adota a proposta de Condoravdi (1992 apud McNALLY, 1993) de que propriedades individual-level distinguem-se de propriedades stage-level no seguinte sentido.

(12) Predicados individual-level são associados a uma inferência de persistência temporal, enquanto predicados stage-level não são. A inferência de persistência temporal especifica o seguinte: se uma eventualidade está ocorrendo em um tempo $t$ e você não possui nenhuma informação de que ela não ocorrerá em um tempo posterior $t$ ', infere-se, então, que ela vai ocorrer também nesse tempo $t^{\prime}$. Essa é uma inferência default, existente apenas se não houver nenhuma informação em sentido contrário. $^{17}$

McNally assume que a referida inferência de persistência temporal se aplica não somente ao futuro, mas também a um tempo $t$ ' no passado. Além disso, a autora observa que existe uma condição de simultaneidade sobre o estado de coisas descrito pelo predicado na oração matriz e pelo predicado secundário. McNally (1993, p. 9) defende que, se essa condição for trivialmente cumprida, isto é, se for inferido que a propriedade denotada pelo predicado secundário se mantém enquanto a propriedade do predicado principal se mantiver, então a justaposição do predicado principal e do predicado secundário será infeliz; se, contudo, essa

${ }_{17}$ Tradução livre do seguinte trecho de Condoravdi (1992, p. 9 apud McNALLY, 1993, p. 9): "Individual-level predicates are associated with an inference of temporal persistence, stagelevel predicates are not. The inference of temporal persistence in effect species the following: if an eventuality is going on at time $t$ and you have no information that it is not going on at some later time t', then infer that it is going on at that later time t' as well. Note that this is a default inference, surfacing only if there is no information to the contrary". 
condição não for trivialmente cumprida, ou se essa infelicidade puder ser explorada para efeitos conversacionais, então o adjunto será licenciado, conforme a autora. ${ }^{18}$

Assim, sob essa análise, segundo explica a autora, predicados adjuntos stage-level seriam felizes em sentenças com predicados principais stage-level em razão de não ser trivialmente o caso de que determinada propriedade stage-level estabeleça uma relação de contemporaneidade com qualquer outra propriedade stage-level. Seguindo o raciocínio de McNally (1993, p. 9) a respeito de um exemplo semelhante, vemos que, na sentença (4a), Maria dirigiu seu carro bêbada, que denota um estado de coisas no qual Maria simultaneamente dirige seu carro e está bêbada, a referida condição de simultaneidade não é trivialmente cumprida: a semântica dos predicados dirigir e bêbada não implica nada sobre o momento em que essas eventualidades ocorrem ou por quanto tempo o evento de dirigir e o de embriaguez perduram. Por essa razão, de acordo com o raciocínio da autora, a justaposição dos dois predicados nesse caso é feliz.

Diferentemente, na sentença (13), com um predicado secundário individuallevel, essa condição de simultaneidade é trivialmente cumprida, razão pela qual essa construção soa estranha quando fora de contexto, de acordo com McNally.

\section{(13) ???Fleisher played the piano intelligent.}

'Fleisher tocou o piano inteligente'.

(McNALLY, 1993, p. 9)

Segundo a autora, em condições normais, se Fleisher é inteligente, então ele será inteligente em qualquer intervalo de tempo em sua vida; consequentemente, é trivial que, ao tocar piano, Fleisher será inteligente enquanto fizer isso. Com isso, nota-se que o predicado secundário é infeliz nessa construção, pois, conforme a autora, ele não contribui para situar temporalmente o estado de coisas descrito pelo predicado principal, assim como este não ajuda a situar o intervalo de tempo durante o qual se dá o predicado secundário.

$\mathrm{Se}$, no entanto, puder ser vencida a inferência de que a propriedade do predicado secundário individual-level se aplica indefinidamente ao seu referente, então a condição de simultaneidade deixa de ser trivialmente cumprida, de acordo com McNally. O dado em (14), repetição de (6b), é utilizado pela autora para exemplificar isso: a saída das meninas do Exército delimita a fronteira que marca o fim de sua defesa do intervencionismo - isto é, as meninas eram intervencionistas antes, mas, quando saíram do Exército, já não eram mais.

They left the Army fervent noninterventionists.

'Elas saíram do Exército não intervencionistas fervorosas'.

${ }^{18}$ Observa-se, em tempo, que McNally assume que os predicados secundários em questão são adjuntos. 
McNally argumenta que até mesmo uma versão de (15) pode ser aceitável se houver um contexto em que o evento de tocar um instrumento marca a fronteira de alguém ser talentoso, como mostra o exemplo em (16).

??Fleisher played the piano talented.

'Fleisher tocou o piano talentoso'.

(McNALLY, 1993, p. 2)

(16) Bill toca saxofone há anos em Pacific Avenue. Seu desejo secreto sempre foi tocar saxofone como John Coltrane, mas, como todo mundo sabe, ele não tem talento algum. No entanto, milagres acontecem: o fantasma de John Coltrane apareceu diante dele ontem e, por um pequeno preço, ofereceu dotá-lo daquela famosa inspiração e habilidade. E hoje, Bill está tocando o saxofone talentoso. ${ }^{19}$

Conforme a autora, a análise pragmática dessas construções prevê também a possibilidade de ser explorada para efeito conversacional a infelicidade decorrente da inferência default de persistência temporal associada a predicados individuallevel. A esse respeito, veja-se o exemplo em (17).

(17) Joe foi para a prova despreparado, ele foi para a prova cansado, ele foi para a prova sem uma calculadora. Mas ele não foi para a prova burro. E aconteceu que ele tirou a nota mais alta da turma, apesar de tudo. ${ }^{20}$

Nesse exemplo, segundo a autora, não há a implicação de que Joe deixou de ser burro ou passará a ser burro em breve, o que mostra que a referida inferência default não foi vencida no caso. Contudo, ainda conforme a autora, a sentença em itálico parece ser licenciada porque a intenção comunicativa da sentença não é introduzir um estado de coisas complexo no qual Joe simultaneamente vai para a prova e não é burro, mas simplesmente declarar que Joe não é burro, de modo adicionar um efeito retórico a essa afirmação (McNALLY, 1993, p. 12).

Neste trabalho, assumo essa análise de McNally para as construções de predicação secundária com adjetivos stage-level e individual-level. Trato a seguir brevemente do fato de que esses adjetivos também podem ocorrer dentro do DP, fora do ambiente de predicação secundária.

19 Tradução livre de McNally (1993, p. 10): "Bill has been playing the saxophone for years on Pacific Avenue. His secret wish has always been to play the saxophone like John Coltrane, but as everyone knows, he's got no talent whatsoever. Yet miracles do happen: the ghost of John Coltrane appeared before him last night and for a small price offered to endow him with that famous inspiration and skill. And today, Bill is playing the saxophone talented".

${ }^{20}$ Tradução livre de McNally (1993, p. 11): “Joe went into the exam unprepared, he went into the exam tired, he went into the exam without a calculator. But he didn't go into the exam stupid. And so it turned out that he got the highest grade in the class, despite himself'. 


\subsection{Internamente ao DP}

Além das construções de predicação secundária, há também outros contextos sintáticos em que podem aparecer adjetivos stage-level e individual-level. Limitome aqui a apresentar dados em que esses adjetivos estão dentro do DP e, portanto, não estabelecem com o nominal uma relação de predicação secundária. ${ }^{21} \mathrm{Meu}$ objetivo nesta subseção é apontar, a partir do trabalho de Cinque (2010), que construções nas quais um adjetivo stage-level ou um adjetivo individual-level estabelecem uma relação de modificação com determinado nominal podem ser analisadas sem a necessidade de se recorrer a uma categoria Asp. Isso é relevante para este trabalho na medida em que indica que a interpretação de transitoriedade ou permanência temporal de um adjetivo, em relação de modificação, independe da presença dessa categoria.

A esse respeito, recorro a dados apresentados por Cinque (2010). O autor mostra que, em línguas românicas, alguns adjetivos, quando em posição prénominal dentro do DP, apresentam somente uma leitura individual-level, ao passo que, em posição pós-nominal no DP, podem apresentar tanto uma leitura individual-level quanto uma leitura stage-level. Isso está ilustrado nas sentenças do italiano em (18a) e (19a), respectivamente, retiradas do autor. ${ }^{22}$

(18) a. Le invisibili stelle di Andromeda esercitano un grande fascino.

b. 'As estrelas de Andrômeda, que são geralmente invisíveis, exercem um grande fascínio’ (individual-level)

c. \# 'As estrelas geralmente visíveis de Andrômeda, que acontecem de estar invisíveis agora, exercem um grande fascínio’ (stage-level)

(19) a. Le stelle invisibili di Andromeda sono moltissime.

b. 'As estrelas de Andrômeda, que geralmente são invisíveis, são numerosas' (individual-level)

c. 'As estrelas geralmente visíveis de Andrômeda, que acontecem de estar invisíveis agora, são numerosas' (stage-level)

(CINQUE, 2010, p. 7) $)^{23}$

\footnotetext{
${ }^{21}$ Uma discussão mais abrangente sobre adjetivos stage-level e individual-level deveria incluir também o contexto de sentenças copulares, nas quais ambos os adjetivos podem ocorrer, a depender do tipo de cópula (e.g. Maria está bêbada / Maria é inteligente), e os contextos em que somente um desses adjetivos pode aparecer — caso das sentenças que, presumivelmente, só aceitam adjetivos individuallevel, como as chamadas construções de small clause complemento (Marcos considera o livro legal / * Marcos considera o livro molhado) e as chamadas construções de small clause livre (Lindo o seu terno! / *Grávida a Joana!). A respeito destas últimas, remeto o leitor a Sibaldo (2009). Deixo para um momento posterior uma discussão mais detalhada desses fenômenos à luz dos resultados apresentados aqui.

${ }^{22}$ As interpretações apresentadas em (18b), (18c), (19b) e (19c), deste trabalho, são traduções de (3b), (3c), (4b) e (4c), do texto de Cinque (2010, p. 7).

${ }^{23}$ Os exemplos em (20) foram elaborados com base em dados de Cinque (2010, p. 7).
} 
O português brasileiro parece comportar-se de modo semelhante ao italiano com relação a esse aspecto. Vê-se, por exemplo, que em (20a) o adjetivo visível, em posição pós-nominal no DP, pode veicular tanto uma leitura de permanência quanto uma leitura de transitoriedade.
a. As únicas estrelas visíveis são Aldebarã e Sirius.
b. 'As únicas estrelas que são geralmente visíveis são Aldebarã e Sirius' (individual-level)
c. 'As únicas estrelas que, por acaso, estão visíveis agora são Aldebarã e Sirius' (stage-level)

Dados como esses levam a, pelo menos, duas conclusões, considerandose as hipóteses que estou assumindo até o momento: (i) no que diz respeito às interpretações stage-level ou individual-level dentro do DP, a ordem é um fator relevante, uma vez que a posição pré-nominal comporta apenas a leitura de permanência temporal, enquanto a posição pós-nominal comporta ambas as interpretações; (ii) existem adjetivos que podem veicular tanto a leitura stage-level quanto a individual-level, como é o caso de visível. Assumindo-se que um adjetivo já entra na derivação com um conjunto de traços stage-level ou individual-level, como estou fazendo neste trabalho, esta última conclusão pode nos fazer supor que, para certos adjetivos, as duas possibilidades de interpretação semântica estão potencialmente contidas em sua prévia informação lexical. ${ }^{24}$

Para explicar essas e outras propriedades dos adjetivos em línguas românicas e germânicas, Cinque (2010) distingue dois "sabores" de adjetivos adnominais, isto é, duas fontes estruturais dentro do DP associadas a propriedades sintáticas e interpretativas distintas dos adjetivos: a fonte de modificação direta, que envolve o merge de APs no âmbito da projeção estendida do NP, e a fonte de modificação indireta, que envolve o merge de APs em uma projeção acima daquela que abriga os adjetivos de modificação direta. Nessa ótica, a fonte de modificação direta, mais próxima do NP, está associada à interpretação individual-level, enquanto a de modificação indireta, estruturalmente mais à esquerda do NP e mais alta que ele, está associada à interpretação stage-level. Dessa maneira, o autor capta a diferença entre essas interpretações em termos estruturais, associando cada leitura a uma posição diferente no DP.

Supondo que esteja correta a análise de Cinque (2010) para os adjetivos adnominais, na qual não há a necessidade de postulação de uma projeção Asp para explicar as interpretações de permanência temporal ou de transitoriedade, concluo que não é função da categoria Asp conferir uma leitura stage-level ou individual-

${ }^{24}$ Outra possibilidade teórica é supor que, nesses casos, não haveria um único item lexical com duas informações, mas dois itens lexicais distintos, cada um com uma dessas interpretações por exemplo, visivel $_{1}$ e visivel $_{2}$. Em princípio, qualquer uma dessas duas possibilidades me parece compatível com a proposta de análise de construções depictivas apresentada aqui. Uma terceira possibilidade é supor que esse tipo de adjetivo ambíguo (ou neutro, indiferente) seria semanticamente esvaziado, e sua interpretação dependeria apenas de outros fatores, como a configuração estrutural da sentença. 
level a um adjetivo, contrariamente ao que defendi em Ferreira (2017), trabalho em que abordo os adjetivos em ambiente de predicação secundária.

Isso não significa, no entanto, que estou dispensando essa categoria funcional na análise de construções de predicação secundária como as que foram discutidas na subseção anterior. Embora assuma a hipótese de que as sentenças com adjetivos stage-level e individual-level internamente ao DP prescindam dessa categoria, argumento que, nas construções depictivas, ela está presente - mas, em vez de desempenhar o papel de descarregar esse tipo de interpretação no adjetivo, ela será responsável por estabelecer uma relação entre duas predicações. Nesse sentido, a presença de uma categoria Asp configura aquilo que considero uma das principais distinções entre os dois ambientes sintáticos aqui estudados, conforme explico a seguir.

\section{REANALISANDO O PAPEL DE ASP EM CONSTRUÇÕES DEPICTIVAS}

Neste trabalho, assumo que as small clauses em construções de predicação secundária apresentam uma projeção funcional Asp responsável por estabelecer uma relação de simultaneidade entre duas eventualidades, aquela denotada pelo predicado da oração matriz e aquela denotada pelo predicado secundário. ${ }^{25}$ Essa categoria estaria presente tanto em predicações secundárias com adjetivos stagelevel, como em (21) (repetição de (4)), quanto em predicações secundárias com adjetivos individual-level, como (22) e (23) (adaptação da tradução de (6b) e adaptação de (17), respectivamente)).

(21) a. A Maria dirigiu seu carro bêbada.

b. Nós comemos os vegetais crus.

(22) Elas saíram do Exército não intervencionistas.

(23) Joe foi para a prova despreparado, ele foi para a prova cansado, ele foi para a prova sem uma calculadora. Mas ele não foi para a prova burro.

Conforme argumentado anteriormente, nos dados apresentados, a eventualidade denotada pelo predicado secundário coincide, de alguma forma, com a eventualidade que o predicado da oração matriz expressa, e essa coincidência temporal é licenciada por razões diferentes. Em (21), com adjetivos stage-level, não se espera que as duas eventualidades em questão sejam, em princípio, simultâneas; com isso, a condição de simultaneidade não é trivialmente

${ }^{25}$ Presumo que Asp estabelece essa relação de simultaneidade entre as duas predicações mediante a adjunção da small clause AspP à oração matriz; ver última seção deste artigo para mais comentários. 
cumprida, razão pela qual as sentenças são boas, de acordo com McNally (1993). ${ }^{26}$ Em (22), com um adjetivo individual-level, a sentença também é feliz devido ao fato de a condição de simultaneidade não ser trivialmente cumprida, mas dessa vez porque a inferência default que associa a propriedade não intervencionistas indefinidamente ao referente de Elas foi vencida, de modo que o predicado principal delimita uma fronteira que marca uma mudança de propriedade: as meninas eram intervencionistas antes de entrarem no Exército, mas deixaram de ser após saírem. ${ }^{27} \mathrm{Em}$ (23), a condição de simultaneidade é trivialmente cumprida, uma vez que não se infere da sentença que Joe passará a ser burro ou deixará de ser burro em breve, mas isso gera uma infelicidade que é explorada para efeitos conversacionais, como já explicado anteriormente.

Neste trabalho, argumento que o papel da categoria Asp nessas construções é precisamente estabelecer as relações de coincidência temporal entre as duas eventualidades em cada caso, sendo essa simultaneidade licenciada por razões diferentes. Disso decorre naturalmente que dados como (24) (repetição de (20a)), que contam com um adjetivo stage-level/individual-level dentro do DP, não apresentam a referida categoria Asp no interior do sintagma que contém o adjetivo: supondo-se que, nesse ambiente sintático, não é estabelecida nenhuma relação de predicação entre o adjetivo e o nominal no âmbito do DP, mas apenas uma relação de modificação (cf. SLEEMAN, 2002), não há razão para a computação ativar a referida categoria Asp.

\section{(24) As únicas estrelas visíveis são Aldebarã e Sirius.}

Como se pode observar, a característica de estar visível (seja permanentemente, seja temporariamente) não é uma eventualidade que se relaciona com o predicado da oração matriz, são. Esse seria o caso ainda que o predicado principal fosse um verbo diferente de ser, como no seguinte exemplo: As únicas estrelas visíveis estão brilhando intensamente hoje. Mesmo neste caso, a eventualidade denotada por brilhar não se relaciona com a propriedade de estar/ser visível, pelo menos não da forma como ocorre nas construções de predicação secundária, pois o verbo da oração matriz predica sobre todo o constituinte as únicas estrelas visíveis.

Adicionalmente, estou supondo que a categoria Asp que integra as construções de predicação secundária aqui abordadas entra na derivação com um dos dois subconjuntos de traços semânticos a seguir: [+PERs], que denota característica de persistência ou permanência temporal, ou [-PERS], que denota eventualidade

${ }^{26} \mathrm{Um}$ dos pareceristas deste texto discordou dessa afirmação, argumentando que pode ser o caso de que, em (21a), Maria já estivesse bêbada antes e continuasse bêbada depois de dirigir, mas que a sentença dá ênfase ao momento em que as duas eventualidades se sobrepõem. De fato, a sentença enfoca a simultaneidade entre as eventualidades. Contudo, o ponto é que, de acordo com o raciocínio de McNally (1993, p. 9), a semântica lexical, em si, desse tipo de predicado (no caso, dirigir e bêbada) não implica nada a respeito de por quanto tempo cada uma dessas eventualidades perdura. Portanto, de acordo com a autora (a respeito de um exemplo similar), nesse tipo de construção depictiva, a condição de simultaneidade não é trivialmente cumprida, motivo pelo qual a justaposição de predicados é feliz.

${ }^{27} \mathrm{Na}$ sentença em questão, intervencionistas deve ser interpretado como adjetivo, não como substantivo. 
temporária (não persistência). Cada uma dessas espécies de Asp seleciona um tipo de adjetivo distinto: Asp [+PERs] somente seleciona adjetivos individuallevel, que entram na derivação com propriedades semânticas compatíveis com esse subconjunto de traços, ao passo que Asp [-PERS] somente seleciona adjetivos stage-level, cujas propriedades semânticas são compatíveis com a propriedade de transitoriedade denotada por este subconjunto. Na derivação das construções de predicação secundária, o adjetivo se moveria e se adjungiria ao núcleo Asp, conforme exemplificado em (25).

a. MOVIMENTO E ADJUNÇÃO DO ADJETIVO INDIVIDUAL-LEVEL PARA ASP [+PERS]

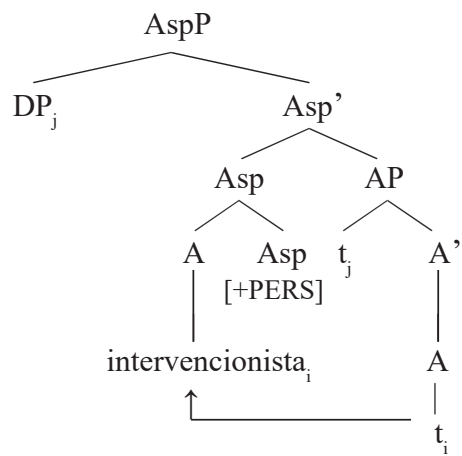

b. MOVIMENTO E ADJUNÇÃO DO ADJETIVO STAGE-LEVEL PARA ASP [-PERS]

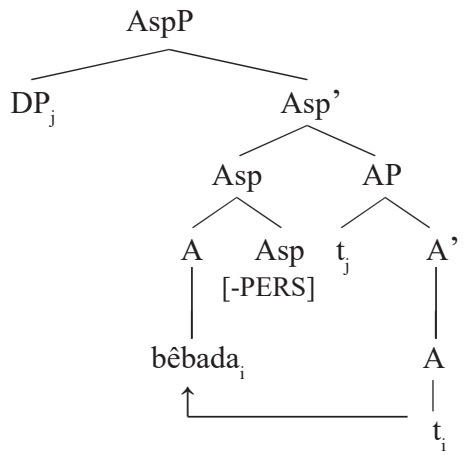

Nessa análise, Asp [+PERs] atua de modo a determinar duas possibilidades: a de que, a partir de um tempo $t$, determinada propriedade não temporária passará a ser (ou deixará de ser) aplicada a um referente, ou a de que determinada propriedade é aplicada indefinidamente a um referente, no passado e no futuro. Na primeira situação, Asp [+PERs] será ativada somente se o predicado da oração matriz for capaz de delimitar a fronteira que marca a mudança de propriedade caso de (22), com o adjetivo (não) intervencionistas. Na segunda possibilidade, Asp [+PERs] será licenciada apenas se houver relevância pragmática para que seja estabelecida uma relação entre a eventualidade do predicado principal e a propriedade que se aplica indefinidamente a um referente - como o efeito conversacional em (23), com o adjetivo burro. O licenciamento de Asp [-PERs], por sua vez, dependeria apenas da compatibilidade entre a eventualidade denotada pelo predicado principal e a eventualidade denotada pelo predicado secundário. ${ }^{28}$

${ }^{28}$ Em construções depictivas, parece haver restrições sobre o tipo de verbo que pode integrar a oração matriz. Por exemplo, verbos estáticos, que não exprimem processo, aparentemente não podem aparecer em construções depictivas, especialmente com adjetivos stage-level: *João tem um carro ansioso $_{i}$ (cf. BISOL, 1975, p. 28-29). Em casos como esse, não haveria a compatibilidade entre o predicado da oração matriz e o predicado secundário a que me refiro. A respeito de restrições semânticas em construções de predicação secundária, ver Foltran (1999, 2002). 


\section{CONCLUSÃO: RETOMANDO OS QUESTIONAMENTOS LEVANTADOS}

Com a nova análise de construções de predicação secundária apresentada aqui, tenho agora condições de retomar os questionamentos apresentados no início deste trabalho. O primeiro foi o seguinte: se Asp for analisado como o responsável por conferir a interpretação stage-level ou individual-level ao adjetivo contido na categoria que toma como complemento, o que significa que qualquer adjetivo poderia, em princípio, ter qualquer uma dessas propriedades, como explicar o fato de que certos adjetivos possuem apenas a interpretação transitória (como grávida, bêbada) e outros, apenas a não transitória (como mamífero, inteligente)?

Com a proposta de reanálise apresentada, essa pergunta não tem mais razão de ser: Asp não é mais considerado o responsável por atribuir a interpretação stagelevel ou individual-level ao adjetivo. Essas propriedades já são parte da informação lexical que o adjetivo traz ao entrar na derivação. A relação entre um adjetivo e Asp em predicações secundárias não seria a de atribuição de propriedade, mas a de compatibilidade de traços na seleção: Asp [+PERs] seleciona adjetivos individuallevel, que denotam persistência temporal, e Asp [-PERs] seleciona adjetivos stagelevel, que veiculam transitoriedade.

Outro questionamento apontado diz respeito ao contraste observado entre (26a) e (26b) (repetição de (1a) e (2), respectivamente):
a. O João leu a carta cansado.
b. *O João leu a carta inteligente.

Pergunta-se, nesse caso, o seguinte: como explicar a agramaticalidade de (26b), dita fora de contexto? Por que Asp seria incapaz de selecionar o adjetivo inteligente nesse caso? Nessa nova análise, isso é explicado da seguinte forma. Supondo-se que a referida sentença seja proferida fora de contexto, a categoria Asp [+PERs], que seria a compatível com o adjetivo individual-level inteligente, nem chega a ser ativada na derivação. Isso ocorre porque a condição de simultaneidade, nos termos de McNally (1993), é trivialmente cumprida nesse caso, pois a eventualidade do predicado da oração matriz, leu, não delimita nenhuma fronteira que marque a mudança da propriedade inteligente atribuída a João, o que resulta numa infelicidade na justaposição do predicado principal e do predicado secundário. Caso essa infelicidade estivesse sendo explorada para fins conversacionais, a sentença seria boa; contudo, sendo a sentença dita fora de contexto e não havendo relevância pragmática, a categoria Asp não chega a ser ativada.

\section{CONSIDERAÇÕES FINAIS E PASSOS FUTUROS}

A análise preliminar que acabo de apresentar contribui para a discussão em torno das construções de predicação secundária no sentido de relacionar a presença de uma categoria Asp, integrante de small clauses depictivas, com a abordagem pragmática de McNally (1993) e sua explicação do licenciamento 
de predicados secundários individual-level em certos contextos. ${ }^{29}$ No entanto, fazendo um balanço deste artigo, entendo que a presente proposta também suscita alguns questionamentos, como é natural em qualquer trabalho, especialmente um que trate de um assunto tão controverso quanto a predicação secundária.

Uma questão especialmente relevante é a seguinte: o que dizer sobre a hipótese discutível, assumida neste artigo, de que stage-level e individual-level são propriedades já contidas na informação lexical do adjetivo que integra as construções depictivas? Tenho ciência de que essa afirmação é um tanto polêmica, mas assumo esse entendimento como hipótese de trabalho. Ao afirmar que o adjetivo já entra na derivação com a informação de que veicula uma propriedade stage-level ou individual-level, estou me guiando por certa noção de que alguns adjetivos expressam tipicamente propriedades não inerentes e outros expressam tipicamente propriedades inerentes, nos termos de Bisol (1975), interpretando essas propriedades como transitoriedade e permanência, respectivamente. Apesar disso, não descarto a possibilidade de a configuração estrutural interferir de algum modo na interpretação desses predicados, ainda que na constituição do próprio sintagma adjetival ou de forma composicional, na interação do adjetivo com Asp ou com o predicado da oração matriz. Não me comprometo ainda com uma explicação de como isso ocorreria: essa é uma questão que merece ser aprofundada em estudos futuros.

Outro questionamento pertinente diz respeito à categoria Asp: como a presença desse núcleo aspectual garantiria a coincidência temporal entre a eventualidade veiculada pelo predicado secundário e a eventualidade veiculada pelo predicado da oração matriz ${ }^{30}$ Neste trabalho, assumi que essa categoria estabelece a relação de simultaneidade entre as duas predicações por meio da adjunção da small clause AspP à oração matriz. Possivelmente, para garantir essa relação de concomitância temporal, o núcleo Asp desempenharia um papel semântico; no entanto, não tenho ainda uma explicação de como isso ocorreria, em detalhes. Também não tenho uma resposta a respeito de qual seria a contribuição do traço [PERs] para a interpretação temporal dos eventos. Por esses motivos, deixo para um momento posterior um desenvolvimento da implementação dessa proposta.

\section{REFERÊNCIAS}

BACH, Emmon. The Algebra of Events. Linguistics and Philosophy, v. 9, p. 5-16, 1986.

${ }^{29}$ De formas distintas da apresentada neste trabalho, outros linguistas também já assumiram o tratamento pragmático de McNally para explicar as restrições existentes em construções de predicação secundária. Foltran (2002), por exemplo, retomando a análise de Foltran (1999), assume a abordagem de McNally (1997) e enfoca a regra de interpretação semântica que permitiria o processamento de tais construções. Ver também discussão em Farrell (2019) e Gumiel-Molina, Moreno-Quibén e PérezJiménez (2016).

${ }^{30}$ Agradeço aos avaliadores deste texto por provocarem parte dos questionamentos indicados nessa seção. Outra questão pertinente apontada por um parecerista, relativa à categoria Asp, é a seguinte: o que significa exatamente a ativação de um traço [+PERs] ou [-PERs] no contexto de um predicado? Esse questionamento, sobre o qual ainda devo me debruçar, permanece em aberto. 
BISOL, Leda. Predicados complexos do português: uma análise transformacional. Porto Alegre: URGS, 1975.

CARLSON, Greg. A Unified Analysis of the English Bare Plural. Linguistics and Philosophy, Dordrecht, v. 1, p. 413-457, 1977.

CINQUE, Guglielmo. The Syntax of Adjectives: A Comparative Study. Cambridge, MA: MIT Press, 2010.

DAVIDSON, Donald. The logical form of action sentences. In: RESHER, Nicholas (ed.). The Logic of Decision and Action. Pittsburgh: University of Pittsburgh Press, 1967. p. 81-95.

FARRELL, Jake. Depictive Secondary Predication and the Correlates of Inner Aspect. U. Penn Working Papers in Linguistics, v. 25, n. 1, p. 97-108, 2019.

FERREIRA, Elisabete. Considerações sobre a sintaxe das construções de predicação secundária depictiva no português brasileiro. 2017. Dissertação (Mestrado em Linguística) - Universidade de Brasília, Brasília, 2017.

FOLTRAN, Maria José. As Construções de Predicação Secundária no Português do Brasil: Aspectos Sintáticos e Semânticos. Tese (Doutorado em Linguística) - Universidade de São Paulo, São Paulo, 1999.

FOLTRAN, Maria José. Predicados secundários: restrições semânticas. Revista Letras, Curitiba, n. 58, p. 211-223, jul./dez. 2002.

GRICE, Herbert Paul. Logic and Conversation. In: COLE, Peter; MORGAN, Jerry L. (ed.). Syntax and Semantics. New York: Academic Press, 1975. v. 3 (Speech Acts). p. 41-58.

GUMIEL-MOLINA, Silvia; MORENO-QUIBÉN, Norberto; PÉREZ-JIMÉNEZ, Isabel. Depictive secondary predicates in Spanish and the relative/absolute distinction. In: TORTORA, Christina; DEN DIKKEN, Marcel; MONTOYA, Ignacio L.; O'NEILL, Teresa (ed.). Selected papers from the 43rd Linguistic Symposium on Romance Languages (LSRL), New York, 17-19 April, 2013. John Benjamins Publishing Company, 2016. p. 139-157.

HALLIDAY, Michael. Notes on transitivity and theme in English, Part I. Journal of Linguistics, p. 37-81, 1967.

KRATZER, Angelika. Stage-level and Individual-level predicates. In: CARLSON, Gregory N.; PELLETIER, Francis Jeffry (ed.). The Generic Book. Chicago: Chicago University Press, 1995. p. $125-175$.

LEGENDRE, Géraldine. Secondary predication and functional projections in French. Natural Language and Linguistic Theory, v. 15, p. 43-87, 1997.

MAIENBORN, Claudia. A Discourse-Based Account of Spanish ser/estar. Linguistics, v. 43, n. 1, p. 155-180, 2005a.

MAIENBORN, Claudia. On the limits of the Davidsonian approach: the case of copula sentences. Theoretical Linguistics, Walter de Gruyter, v. 31, n. 3, p. 275-316, 2005 b. 
MAIENBORN, Claudia. On Davidsonian and Kimian states. In: COMOROVSKI, Ileana; HEUSINGER, Klaus von (ed.). Existence: semantics and syntax. Netherlands: Kluwer Academic Publishers, 2007. p. 107-130.

McNALlY, Louise. Adjunct Predicates and the Individual/Stage Distinction. 1993. Trabalho publicado posteriormente em: DUNCAN, E.; FARKAS, D.; SPAELTI, P. (ed.). The Proceedings of WCCFL 12, 1994.

McNALLY, Louise. A semantics for the English existential construction. New York: Garland Press, 1997.

NUNES, Jairo. Linearization of Chains and Sideward Movement. Cambridge, MA: MIT Press, 2004.

ROTHSTEIN, Susan. The syntactic forms of predication. Tese (Doutorado) - Cambridge (MA), Massachusetts Institute of Technology, 1983.

ROTHSTEIN, Susan. Secondary Predication. In: EVERAERT, Martin; RIEMSDIJK, Henk van (ed.) The Blackwell companion to syntax. Blackwell Publishing, 2006. p. 209-233.

SCHULTZE-BERNDT, Eva; HIMMELMANN, Nikolaus P. Depictive secondary predicates in crosslinguistic perspective. Linguistic Typology, v. 8, n. 1, p. 59-131, 2004.

SIBALDO, Marcelo Amorim. Qual a estrutura das small clauses livres do português brasileiro? Revista Letras, Curitiba, n. 78, p. 125-145, maio/ago. 2009.

SLEEMAN, Petra. Adjectival agreement within DP without feature movement. In: SATTERFIELD, Teresa; TORTORA, Christina; CRESTI, Diana (ed.). Current Issues in Romance Languages. Amsterdam/Philadelphia: John Benjamins, 2002. p. 301-316.

STOWELL, Timothy. Subjects across categories. The Linguistic Review, v. 2, p. 285-312, 1983.

WILLIAMS, Edwin. Predication. Linguistic Inquiry, v. 11, n. 1, p. 203-238, 1980.

Recebido: $2 / 1 / 2020$

Aceito: $24 / 6 / 2020$

Publicado: $30 / 7 / 2020$ 